\title{
Poland in the Last Quarter of the Twentieth Century: A Panel Discussion
}

\author{
ADAM BROMKE, Chairman \\ ZBIGNIEW BRZEZIŃSKI \\ ZBIGNIEW FALLENBUCHL
}

\author{
ALEXANDER GELLA \\ LESZEK KOŁAKOWSKI \\ ANDRZEJ STYPUEKOWSKI
}

\section{Chairman:}

Our discussion coincides, almost exactly, with the thirtieth anniversary of the end of hostilities in Europe. Our objective is to review Poland's experiences during those thirty years and to project our study into approximately the same period in the future, that is, into the opening stages of the twenty-first century.

In 1945 we were all on the verge of manhood-the oldest panelist was twenty-three and the youngest sixteen. In the year 2000 those of us who survive will be over seventy. Our discussion, then, is likely to have some personal overtones-we shall be reviewing the period of history which corresponds to the most active part of our own lives. We are apt to look at events around us not only as witnesses but also, to a lesser or greater extent, as participants. In short, we shall be offering the perspective of the generation born in the 1920s and which has now reached middle age. Incidentally, it is not without some symbolic significance that five prominent members of the generation of the Columbuses (pokolenie Kolumbów), as we are known in Polish, are holding a discussion on Poland on the other side of the Atlantic. Our observations inevitably will be colored by our own personal experiences, and in this respect the members of the panel differ considerably. First, we left Poland at different times. Second, the panelists come from several different countries today. Finally, even though the theme of our discussion is primarily political, the panelists are drawn from various disciplines.

It would be fitting now, I think, to start our discussion by citing a passage from an address Professor Brzeziński delivered earlier:

I would suggest that if there is to be a Poland which fulfils many of the Polish national aspirations which most of you share, it will have to be a

Poland which lives in a more decent and more cooperative world order.

Held at the Third Congress of the Polish Institute of Arts and Sciences in America, McGill University, Montreal, on May 16, 1975. 
That, without such a more decent and cooperative world order, one will not have the Poland which one desires. The continuation of the cold war, heightened tensions between America and the Soviet Union, will narrow the margin of freedom and the opportunities for change for Poland. There are still occasionally those who find psychological satisfaction in heightened tensions between America and the Soviet Union. Let us have no illusions about it, heightened tensions will not bring about either a more decent world or a Poland which fulfils its own destiny more freely. Nor will Poland be able to shape its destiny more freely if America withdraws from the world. For American isolationism, American indifference to world affairs and to the social dilemmas of our time, will make for a world which is far less stable, more chaotic, more anarchistic, in which a community of centrally controlled and highly dominated states, such as the Eastern bloc, will find it relatively easy comparatively speaking, to sustain itself. It is only by seeking a more just, more cooperative and a new international order that we can fulfil those aspirations which we share first of all as human beings, secondly as individuals and thirdly as people of Polish origin. ${ }^{1}$

\section{Z. Brzezinski:}

My task is to discuss Poland's prospects for the next quarter of a century in the international context. It might be a truism to say that we now live in an age of interdependence; but it is a fact that one of the very basic changes that has transpired on the world scene is the new reality of interdependence between nation-states. The notion of nation-states as absolutely sovereign entities no longer has feasibility-it belongs to an age in history which is no longer with us. But for Poland, of course, the present situation is not one of interdependence but of dependence. This dependence is on an external power which heavily influences the course of Polish political life, as well as Poland's foreign policy. Thus, the question within the purview assigned to me is whether the situation can be altered, and, if so, in what fashion.

As I think of the future I can envisage essentially four alternative contexts for Poland, or four alternative situations in which Poland could conceivably find itself at some point in the future. The first would be one which is still very dear to many and which has a certain touch of nostalgia to it. This would be a situation of complete independence-an independence as complete as that which prevailed prior to 1939 . The second situation would be one of relative independence. This would be a Poland more related to other East European countries and having closer ties with the West and thus not so fully

1. Keynote address, "The International System: Crisis and Change," by Dr. Zbigniew Brzezinsski to Third Congress of the Polish Institute of Arts and Sciences in America held at McGill University, Montreal, on May 16, 1975. 
dependent politically and ideologically on a contiguous power which happens to be much stronger than itself. The third alternative would be that of continued dependence, that is, the maintenance by and large of the present situation in which Poland is highly influenced, ideologically, politically, and indeed, alas, even culturally, from the outside. And finally, as a fourth alternative, there is the possibility of absorption by the Soviet Union. That is to say, Poland would become the sixteenth or perhaps the seventeenth republic of an enlarged Union of Soviet Socialist Republics. These are the four basic alternatives that can be envisaged when one speculates about the position of Poland in the next twenty-five years.

Now, what are the conditions that might make any one of the foregoing alternatives more or less likely? I should think that, at the very minimum, a totally independent Poland would require a virtually complete collapse of the Soviet Union. It would involve a process whereby the Soviet Union disintegrates through a conjunction of internal and external forces. One can imagine, for example, a war with China embroiling the Soviet Union in a prolonged and destructive conflict. The possibility of war with the United States, nuclear though it would be, raises interesting questions about whether it could be confined only to the Soviet Union. An internal fragmentation within the Soviet Union resulting, in all probability, in independence for some Soviet non-Russian nations, such as the Ukraine and Belorussia, might occur. Moreover, in order to have a completely independent Poland, the paralysis in the Soviet Union would have to be accompanied by the absence of a reunified Germany. Disintegration of the Soviet Union followed by reunification of Germany might also pose a threat to Poland. As you can see, this is a rather tall order of circumstances.

The second alternative, relative independence, would require positive evolutionary changes in the Soviet Union toward a more democratic and pluralistic order as well as a relatively stable, attractive, and forceful West, and a Western policy which would encourage closer relations between Eastern and Western Europe without precipitating countervailing Soviet responses. In other words, this would require a process of gradual pluralistic evolutionary change which would quietly transform the context in which Poland finds itself.

The third alternative, continued dependence, is easiest to define because it essentially means a continuation of the present circumstances: the USSR would remain strong, the West would not be fully unified. Therefore, no fundamental changes in the present international framework would occur.

The fourth possibility, absorption of Poland by the Soviet Union, would presumably be preceded by more nationalistic, assertive political developments within the Soviet Union-a combination of militant ideology with big power nationalism, and a conceivable transformation of the Soviet regime from a 
party dictatorship into a party-military dictatorship. There are some grounds, incidentally, for suspecting that in 1945, some of the top Soviet military command was urging upon Stalin the quick exploitation of the then prevailing circumstances for the transformation of Poland into a Soviet republic-a recommendation that Stalin did not adopt, largely for reasons of foreign policy. This alternative would have to be accompanied, I would assume, by a major weakening of the West and particularly, by American disengagement from Europe.

What are the prospects and what are the preferences? I would say that present trends favor largely the third alternative and one should not even entirely exclude the fourth. Present trends clearly are for continuity, for there is little indication of a basic change in the asymmetry of power and influence that prevails between Poland and the Soviet Union. Furthermore, there are some dangers on the horizon which should not lead one to exclude altogether the fourth alternative. But one would certainly be wrong to project present trends totally into the future. If history teaches us anything, it is that the worst way to predict the future is to see it as an extension of the present. History is full of dramatic discontinuities and sudden changes. Hence, it is not irrelevant to ask what our preferences are.

Speaking for myself, I would say that alternative two is clearly my preference, that is, a relatively independent Poland within an increasingly interdependent European framework and in an increasingly interdependent world. I would think it unrealistic and nostalgic to hope for the first. That kind of a world as a whole is not going to be re-created again, not to speak of the uniquely unfortunate geographic and historical circumstances of Poland were it to be re-created. But the second alternative is attainable and might come about. I would like to conclude with the thought that this is something to which Poles within Poland and Poles abroad can aspire and for which they can work quite intensely. History changes dramatically, and one should not shape one's goals only on the basis of prevailing circumstances. National goals and visions ought to be beyond the horizon of the immediate. A nation lives only as long as it has goals that it seeks, even if at the moment they are not attainable. Hence, I do not believe for a moment that Poles in Poland or Poles abroad should accommodate themselves either to the third or to the fourth reality. There is a realistic, modern, and historically compatible alternative, namely, a Poland as part of a larger community. This is intellectually appealing and is in keeping with the thrust of the times. It is also an aim which can cut across ideological lines, within Poland and abroad, and it is something to which Poles abroad can contribute. The many Poles in Europe, Canada, and in the United States may contribute in various ways to the shaping of a more interdependent Europe and, by doing so, also contribute to a situation in 
which, in the next quarter of a century, Poland very concretely, very significantly, improves its national condition.

\section{Kotakozuski:}

To extrapolate existing trends into the future, as Zbigniew Brzeziński has just now correctly pointed out, is the least reliable method of prediction; for we know that all kinds of developments, in all domains of life, eventually break down. Thus we are more or less doomed to futile speculation, but, it must be admitted, it is difficult not to be tempted at times to engage in this sort of activity.

Now, within these limitations, we may say that one of the most characteristic features of the whole development in the so-called Socialist countries of the Soviet bloc in the last few years has been ideological decline, or ideological decomposition, which means that the totally binding, obligatory state ideology is practically dead. Neither the rulers nor the ruled believe in it any more. This paper ideology no longer has any well-defined content because there is no one single authority to define it or to enforce it. The real ideological life in these countries no longer corresponds even to the basic stereotypes of the ideology. One may also safely say that by the late 1960 s even the so-called "revisionism" in these countries came to an end. This meant that attempts to criticize or to improve the existing system by appealing to the values and theoretical alternatives which this system ostensibly admitted, stopped for all practical intents and purposes. So we face a new situation-new because, in contrast to democratic systems where the legitimacy of power is assured by representative mechanisms, in the Soviet system the legitimacy is to be found only in its ideology. There is nothing but ideology to justify the existing distribution of power. Ideology is built into the very mechanism of government and the rulers absolutely cannot afford to abandon it.

In this context one can, for instance, appreciate the controversy between Solzhenitsyn and Sakharov about the role of ideology. Roughly speaking, Solzhenitsyn claims that the Soviet state, in both foreign and internal policies, in economic as well as political spheres, is under the overwhelming influence of a false Marxist ideology, and it is this ideology which is responsible for all the disasters of the society and the state. Sakharov replies that the official state ideology is dead, that nobody takes it seriously any more, so it is silly to believe that ideology is a real force shaping the policies of the state. It seems to me that both of these views are true to some extent. The ideology in which virtually nobody believes is still binding and has to be followed by all. The real motivations which shape policy cannot be revealed even if they are well known to everyone; they cannot be revealed without undermining the entire system of power. 
Normally one characterizes the most important forms of ideological life in the Soviet Union according to certain schemata. There is, first, the concept of a strongly nationalistic, imperial Russian character; a kind of Bolshevism without Marxism. Second, there are liberal social democratic ideas of the Western type for which Sakharov is the most eminent representative. Third, some revisionist ideas persist, appealing with conviction, or perhaps halfconviction, to the stereotype of the existing ideology in an intent to return to genuine Marxism or even to genuine Leninism. The brothers Medvedev are the best known and most eminent representatives of these tendencies. Fourth, we have the nationalist aspirations of the non-Russian peoples in the Soviet Union. And finally we have religious movements.

It is normally assumed, and rightly so I believe, that the strongest potential disintegrative forces in the whole system are the nationalistic aspirations of the non-Russian nationalities. And in the Soviet Union, these ideas and movements are exposed to the most severe persecution. The so-called revisionist ideologies, with hopes of returning to genuine Marxist philosophy, to Marxist ideology, or to what some people think was Leninism, seem to be very weak. One should stress, however, that the particular force of this sort of ideology lies in its appeal to the same stereotypes and traditions as those of the ruling party. In other words, this ideology speaks with a voice that may be heard within the party, and at times of crisis it has always had great impact as a disintegrative force within the ruling apparatus (which has been more or less immune to ideas rooted in other traditions and appealing to other philosophical and ideological stereotypes).

In Poland, this sort of revisionism in the ideological or intellectual sphere is rarely found. People, both old and young, have simply stopped thinking of going back to "genuine Marxism," or to "socialism with a human face." In other words, communism has ceased to function as a valid reference system in ideological discussions. There are nationalistic ideas to be sure. Various different forms of nationalism, religious traditions, and liberal ideas serve as the reference system in the ideological life in Poland. But there is no reason whatsoever to expect that the official state ideology-the official Communist doctrine, which is uncertain of itself and which is believed by no one, not even its official spokesmen-can still be revived as a real force. It is also very doubtful that the revisionist ideology could be revived. The gap between the realities of spiritual life in our country and the official state ideology will certainly deepen and become more and more glaring in the future. The outcome of this process really cannot be predicted on the basis of any historical analogies. We face basically a new situation in which it would be futile to look for analogies in the past.

Our cultural and ideological situation is in one important respect both simpler and easier than in Russia. We are a country which is not sovereign, 
or which at best is only half-sovereign, and our main preoccupation is with one specific question: political independence of our country. It is extremely important always to have this ultimate goal before our eyes and to refer to it in our particular activities.

At the same time our main concern should be to refrain from becoming anti-Russian nationalists, which, in turn, cannot but stimulate anti-Polish nationalism in Russia. It is of paramount importance for us to make a distinction between anti-Soviet and anti-Russian attitudes. It is important that we maintain friendly contacts with the Russians, as well as with Ukrainians, Belorussians, and Lithuanians, because our aspirations can never be satisfied if we presuppose that we live, and that we will always live, among eternal enemies. In that case, we could be helped only by external force, which would most probably be a world war. Obviously, one could hardly imagine a worse disaster both for Poland and for other countries.

\section{Z. Fallenbuchl:}

I should like to concentrate on several economic factors which in my opinion will likely play an important role in the next few decades. I shall comment on their possible effect on the overall performance of the Polish economy and speculate about the probable reactions of the leadership to the challenge these factors will create for them, for these reactions themselves may, in turn, create new problems affecting the development process.

The most important are likely to be the demographic factors. According to available projections, Poland's population will increase from 34.0 million in 1975 to 38.9 million in the year 2000. Incidentally, on the basis of existing projections, the relative position of Poland in size of population will decline from 0.85 percent to 0.60 percent of the total world population; from 7.10 percent to 6.85 percent of the total population of Europe; and from 13.33 percent to 11.82 percent of the population of the Soviet Union.

Population in the "productive group," defined as men from 18 to 64 years of age and women from 18 to 59 , will increase from 19.96 million in 1975 to 22.48 million in 1990 and 23.68 million in 2000 . While this group of population has increased by 1.63 million between 1970 and 1975 and will still increase by 1.41 million from 1975 to 1980 , the increases in the subsequent fiveyear periods will be considerably smaller: 707.0 thousand in 1980-85, 395.6 thousand in 1985-90, 559.8 thousand in $1990-95$ and 645.9 thousand in 19952000.

The impact of demographic factors will be particularly strong in agriculture, where as the result of the migration movements of 1950-70 the sex and age composition has become distorted and is expected to be distorted even more seriously in the future. The relative shortage of labor in nonagricultural activities will probably further stimulate the pace of migration from agricul- 
ture. It is expected that at least 2.2 million people will have to be shifted from agriculture during the period 1971-90 to meet nonagricultural labor requirements. An additional 1.3 to 1.6 million are expected to leave agriculture in the years 1991-2000.

In order to maintain the average rate of growth of agricultural production for 1971-2000 at the same rate as in 1961-70 (3.2 percent per annum), the average annual rate of growth of labor productivity must be about 5 percent, or the rate at which labor productivity increased in industry in 1966-70. The average annual rate of growth of labor productivity in agriculture was only 2 percent during 1950-70. It is doubtful that such a considerable increase in the growth of labor productivity can occur, especially considering the expected deterioration in sex and age composition of the labor force-unless some drastic institutional changes occur.

The proportion of small uneconomical farms is very high in Poland. In 1970, 57.9 percent of all individual farms were smaller than 5 hectares and another 30.9 percent had from 5 to 10 hectares, while, for example, farms in Denmark of the corresponding sizes represented only 9.4 and 21.3 percent. Thus, Polish agriculture is relatively backward and ill-prepared for accelerated growth and for appropriate changes in the composition of output, rapid improvements in yields and labor productivity, and for overall modernization.

It is highly unlikely that the challenge of a declining agricultural labor force and of the requirement for increased and restructured agricultural output will induce the leadership to liberalize agrarian policy to permit the required increases in the average size of private farms, drastic increases in material incentives, and marked improvements in the living conditions in rural areas. There are some signs that the challenge will call forth only accelerated "socialist reconstruction" of agriculture. In recent years the number of individual farms has been declining as the result of granting retirement pensions to older farmers in exchange for their land. It seems that the main agrarian farm envisaged for the future is not the collective farm, which is regarded as a relatively primitive institution, but a modern, highly specialized and mechanized state farm. Labor productivity is likely to improve, but the record of state farms in Poland suggests that capital intensity will increase sharply as well, and yields will nonetheless remain relatively unimpressive.

There are grounds, therefore, to expect agriculture to become the main if not the major problem area seriously hampering the development of the whole economy. Unfortunately, a deadlock seems inevitable here. Rapid and far-reaching modernization of agriculture, without which the expected outflow of labor from agriculture would reduce output and make improvement in the product mix and better utilization of scarce arable land difficult, must take place. However, with other alternatives excluded, the process of modernization has to assume the form of socialization of agricullture, which cannot be 
effected quickly. Apart from the political risks involved in any attempt to accelerate the process, there are also some serious economic limitations. The pace of the reconstruction of agriculture can have a considerable impact on the structure of industrial production, on the structure of international trade, on the availability of labor for nonagricultural activities and, therefore, on the rate of growth of national income. If the pace is relatively slow, there may be a shortage of labor in the rest of the economy. At the same time, however, a large volume of investment funds, which would otherwise have to be used in agriculture, could be utilized for the modernization of other sectors of the economy. If, on the other hand, a policy of accelerated reconstruction of agriculture is introduced in the 1980 s, a considerably larger volume of investment funds will have to be used for technical reconstruction and for the creation of an expensive infrastructure for the socialist agricultural economy. This policy would release large reserves of manpower from agriculture, but it might also create serious competition for the modernization program in industry and for the development of infrastructure for the rest of the economy.

Demographic trends will also have a considerable impact on the development of industry. Until now the growth of industrial output has depended mainly on the increase in employment. Increases in productivity have had a relatively small impact on the rate of growth of production and have been effected at the price of large investment outlays. As early as the mid-1960s this situation was recognized as unsatisfactory and efforts have been made to replace the "extensive" pattern of development with an "intensive" one, in which increases in the productivity of labor and capital, rather than in their quantities alone, would become the main determinants of rates of growth. So far there has been no success. Even the exceptionally high rates of growth since 1971 have been based on high rates of employment increase and investment. While the average annual rate of growth of investment outlays in the economy in 1971-75 was planned to be below the 1966-70 rate (7.8 percent as compared with 8.1 percent), it is now estimated to reach a figure twice as high (17.0 percent).

In the future, as the possibility of further rapid growth in industrial employment becomes increasingly more limited, acceleration of labor productivity becomes a necessary condition for high rates of growth of industrial output. For the time being the high rate of investment has been financed by a large import of foreign capital. This explains why in 1971-73, national income produced within the country increased at the average annual rate of 9.7 percent, and national income distributed (the aggregate expenditure on consumption and investment) increased by as much as 12.7 percent. It was, therefore, possible to provide significant improvements in consumption along with an increase in the share of accumulation in national income (Marxist 
definition) to 29.3 percent in $1971,31.6$ percent in 1972, and even 34.5 percent in 1973. These are extremely high rates. They considerably exceeded the previously established highest rates of accumulation of 1953 (28.1 percent), 1968 (28.5 percent), and 1970 (27.9 percent), which each time caused hardships and dislocations within the economy. This is, however, a short-run maneuver. In the long run such high rates of capital accumulation would simply be impossible to achieve. Increases in labor productivity would have to be accompanied not by increased capital intensity but by increases in the productivity of capital.

Unfortunately, as has been pointed out by the chairman of the State Planning Commission, Mieczysław Jagielski, it is necessary to expect a considerable increase in capital intensity in the growth process and a relative shortage of capital in relation to the requirements. There are several reasons for this situation: (1) it will be necessary to invest in the expansion and modernization of the infrastructure which was to a great extent neglected in the past (the so-called "nonproductive" investment is planned to grow at a higher rate than the "productive" investment during the twenty-year period $1971-90) ;(2)$ there will be some increase in the cost of investment because more attention will have to be paid to the ecological factors; (3) there is a need to replace a large proportion of worn-out or obsolete machines and equipment in industry, and some branches, for example, iron metallurgy, will have to be completely reconstructed; (4) the expansion of the "domestic raw materials and fuel base" will have to be continued, and mining is a highly capital intensive industry with a long gestation period; (5) some investment will be required to reduce material intensity and to reduce, therefore, the pressure for an even greater expansion of the exploitation of domestic, often unprofitable, sources of raw materials and to reduce the rapidly increasing import of raw materials; and (6) because of the demographic situation and the requirement for labor in agriculture and construction and in order to expand services, some capital will be required for substitution against labor, particularly as the conditions of general labor shortage in the economy become acute in the 1980s.

Increased capital intensity and reduced directly-productive investment will tend to reduce the rate of growth of industrial production and national income. It will then be increasingly more difficult to avoid reducing the rate of increase of consumption. In other words, it will be difficult to plan for growth without repeating the policy which resulted in serious stagnation in the past-particularly during the second half of the 1960s. However, without high rates of accumulation the volume of investment outlays will have to be limited unless it proves possible to continue to import foreign capital at a substantial rate. A reduction in the rate of growth of investment accompanied 
by an increase in capital intensity will reduce the rate of growth of national income and tend to reduce even more the role accumulation can play.

In order to avoid this vicious circle, it will be necessary to make three determined efforts: (1) to effect significant structural changes in industry by the elimination of the least efficient industries and by the priority expansion of those with the highest overall factor productivity; (2) to stimulate technological progress not only by larger outlays on fundamental and basic research but also by creating strong and effective mechanisms for inducing and stimulating the demand for technical and organizational innovations; and (3) to increase the degree of specialization and production for export in order to increase the scale of production and thereby reduce costs, and to concentrate scarce investment resources, managerial talent and, above all, research and development efforts in a few carefully selected fields.

These problems are interrelated. In the words of a Polish economist, M. Nasiełowski: ". . . detrimental structural tendencies of our development, together with the low sensitivity of the national economy to organizational and technical innovations and an inability to utilize the results of scientific research, have in effect limited the expansion of export and the economic advantages which can be derived from international trade, as well as the supply of the domestic market and the ability to keep it in the state of equilibrium."

A considerable challenge will, therefore, be created for the political leaders. A successful policy would require decentralization in the decisionmaking process, limitation of central planning, and exposure of the economy to a higher degree of domestic and foreign competition. So far very little has been done in this direction. Various ad hoc measures-import of foreign capital, restructuring of the economy "from above" through the decisions of the central planners, and the stimulation of scientific and technical progress by increased outlays and strengthening of the research and development facilities-have been adopted by Gierek's group as a substitute for systemic changes.

Again it is doubtful whether, when faced with difficulties created by the shortage of capital and labor, increased capital intensity, and insufficient increase in labor productivity, the leaders would be willing, and indeed able because of the Soviet pressure, to choose the policy of bold economic reform. More likely, when faced with these difficulties they will instinctively seek to increase the degree of centralization, a reaction that will aggravate the situation and might again lead to economic stagnation.

Particularly, it is doubtful whether, when faced with the balance of payments difficulties which are aggravated by the unfavorable developments in the world markets, the leaders will be prepared to continue a policy of discarding the industrial structure based on import substitution and to expand 
the export sector significantly. Without making these changes, however, it will not be possible to import modern machines from the West on a continuous basis as is necessary for rapid modernization of the economy. It is more likely that they will again rely on a policy of partial autarky at the cost of perpetuating an inefficient economy. They may be satisfied to direct trade even more to the "soft" CMEA markets, accepting in consequence a lesser degree of technological sophistication and lower efficiency. This decision is quite probable because the Soviet Union is likely to continue and to strengthen pressure for the integration of the CMEA countries.

A particularly serious problem which I think Poland now faces is the fact that Polish industry was built strictly for domestic requirements and not as a part of the world economy. Its growth was of what is called the inputsubstitution type, and the result is that everything is produced on a very small scale. Costs are, therefore, extremely high. It is impossible to maintain modern, well-advanced standards of production in all the industries which have been developed. As a result a good part of the industrial structure is really obsolete.

I would like to make a comparison here with the situation which existed before the war. Between the wars the Polish government had the full support of everybody to do one thing: to build up the Polish army. Tremendous sacrifices were made to strengthen the Polish armed forces, but only certain parts of the Polish military machine were really good. Poland was probably the country with the best and largest cavalry - at the time when cavalry lost its significance. And the same, I am afraid, is happening now in the economic sphere. In the name of building up industry, tremendous sacrifices have been asked and made, but the industrial structure constructed in the early 1950s was basically patterned after nineteenth-century British and German models. In the latter 1950s, when the danger of such a development was pointed out, that same structure had to be completed because so many investments had been started and had to be finished.

Now the only way the Polish economy can really become efficient, the only way in which labor productivity can increase, is by the opening up of the Polish economy and the production of some specialized items for export to the Western markets. There are two ways of doing it. One way is, of course, to effect a greater degree of integration within the Comecon. The other is to move outside the Communist bloc to trade with the West. Unfortunately, I believe, the trade within the CMEA places Poland in a position of producing things which are really not economical. There is no time to go into details but it is a form of exploitation. It is not that Poland is not getting the world price; on the contrary, frequently the prices are even better than those which Poland can get outside of the Communist bloc. But Poland is producing certain things 
exclusively for the Soviet market which otherwise would not have been produced in Poland at all and, indeed, will never be produced efficiently at a low cost. So it is extremely important for the Polish economy to try to export to the West and in exchange to get modern technology in the form of licenses and modern machinery.

In the light of the above comments it seems unlikely that the Polish economy will be able to achieve the 7.5 percent average annual rate of growth of national income which is assumed in the official perspective plan for the period 1971-90 or even the 7 percent rate accepted in some semi-official projections for the period 1971-2000.

\section{A. Gella:}

Predicting the future sociocultural development of Poland can proceed along one of two lines. One can try to formulate a prognosis within the framework of present political conditions and existing international structuresthat is the easier way-or one can attempt to anticipate history's introduction of profoundly new situational factors and parameters which cannot today be easily defined or envisioned. This second way is incomparably more difficult; yet drastic upheaval, if only for the economic reasons which Professor Fallenbuchl just presented to us, seems more likely to be in store than stability and continuity.

Needless to say, to take the second way and assume the eventuality of drastic political upheavals would embroil the panel in an intensive political debate which time will not allow. Therefore, I will restrict myself-though with reservations - to presenting some features of a prognosis for Poland based on the assumption of another twenty-five years of relative international stability and of peaceful development within the country itself.

In Poland, the futurologists of the "Committee of Prognostication: 'Poland 2000'" focus on the major trends in the development of Polish society such as demography, education, urbanization, industrialization, consumption, housing policy, social macrostructure, and participation in cultural life. All these topics concern spheres of national life directly controlled by the policy of the state. However, outside the scope of the Committee's studies lie large sectors of informal social life which are beyond institutional controls. I would like to consider two of them: the first related to the renaissance of Catholicism, and the second related to changes in the Polish geopolitical situation. Both cause me to look into the future with some optimism.

In Polish social life two centers-the Communist party and the churchexert dominant influences upon the spiritual, social, and cultural life of the nation. They espouse two opposite models of culture. The party advocates a model characterized by monopoly of power, a materialist Weltanschauung 
of ideological egalitarianism, and the modernization of life along patterns borrowed from the Soviet Union, though with a sufficient dose of nationalism to appeal to the masses. In this model Poland is seen as one of many Communist states, basically similar to all of them and playing a dependent position role in the Communist bloc.

Poland, however, will always remain dissimilar to other countries in the bloc because of the second center, represented by the Catholic church and various groups of independent intellectuals. They defend a cultural model whose main features might be summarized as follows: political pluralism, philosophical dualism, Western liberalism integrated with Polish national tradition, and Christian universalism. It is interesting that there are more and more intellectuals who, in spite of their personal religious indifference or even their lifelong opposition to the church as a bastion of social reaction, finally discover its other face and adopt its cause as their own.

The second half of the twentieth century is witnessing, paradoxically, a severe decline of transcendentalism in Western Christianity and simultaneously a deepening of the transcendental element in the life of the "silent churches" in the Communist countries. To understand the roots of this trend one must recognize that, denials from both sides notwithstanding, there is an important kinship between Christianity and communism. Marxist communism rejected the transcendental and metaphysical elements of all religion, but it took over the ideas-though expressing them in a strictly materialistic way-of the social gospel. Thus, in the capitalist West the decline in transcendental feelings has been accompanied by growing emphasis upon the social gospel. In the Communist countries it is the state, not the church, which is attending to the social gospel's realization. This aspect of communism explains much of its attractiveness not only to the poor but also to the intellectuals in the West who are thirsty for an intellectualized ideology involving the old virtue: doing good for your neighbor.

Ironically, and in marked contrast to the situation in the West, the usurpation of the traditional social gospel of Christianity by the state has produced in the Communist countries a great resurgence of the sacred force of transcendentalism among both the Christian masses and the centers of religious thought. This is of special significance in Poland. The Polish Catholic church has been able to keep its independence to an extent unknown in the other countries in the Communist bloc, and, thereby, has provided a haven for the intellectual activity of all those who defend the continuity of Western Christian tradition.

What does this mean for the future of the Polish nation, as seen against the background of world developments? About nine hundred years ago the Polish king, Boleslaw the Bold, murdered the bishop of Poland, Stanislavus. 
"The blood of martyrs is the seed of the Church," as the saying goes, and for centuries thereafter Poland was a faithful daughter of the church. Indeed, Polish Catholicism finally became so much a part of the national culture that it lost its religious depth. Now, for the first time during Poland's thousandyear history, Roman Catholicism has become a religion which is in fundamental opposition to the official state ideology. Yet the reduction of the earthly realm of the church in Poland transformed it into an even greater spiritual force in the country. The center of the intellectual world confict between transcendentalism and materialism seems to have moved from the banks of the Seine to the banks of the Vistula.

Social and intellectual consequences of this confrontation will to a large extent determine Poland's future place among the nations. This is not to deny that industrialization, urbanization, and modernization-organized and directed by the party-are causing a process of de-Christianization within many social groups. Still, a deepening of religious consciousness and belief is penetrating even those social groups which might theoretically be expected to be the most inclined to accept the materialistic attitudes: the working class and the student youth. The party's concentrated effort to detach these groups from religion has not been matched by practical results.

The separation of the church and the state and the partial nationalization of church property only brought the church closer to the people. In the new conditions the church could demonstrate to people the actual sense of its calling. The old proletarian anti-clericalism has been undermined by the fact that the clergy is no longer an ally of the ruling class. The secularization of education destroyed the basis for treating religion as a part of the culture of the establishment. Youth always tends to be attracted by the forbidden fruits in a search for absolute truth and justice-the church offers both of them. For these reasons the party's campaign against the church has remained unsuccessful.

The second factor which will determine Poland's future is its geopolitical situation. By this I do not mean Poland's new political boundaries, but its place in the new configuration of world political and ideological forces. For centuries Poland lived on the outskirts of Europe, on the frontier of its civilization. Today, Poland finds itself at the crossroads between two opposite and competing world camps and several sociopolitical ideologies. This is a fact of great promise for Poland's social and cultural development.

It is a well-known sociohistorical truth that a rapid development of culture always occurs in areas of multiplied cultural contacts. The most evident examples of this are: the flourishing of ancient Greece when her cultural contacts were intensified in the fifth century B.C., the rapid development of northern Italy when the Crusades placed this poor country at the crossroads of East 
and West, and later the remarkable rise of England when its central position between various continents contributed to its multiple mercantile and cultural contacts. Likewise, there were many causes for the "Golden Age" of Poland in the sixteenth century, but one of them clearly was that the Polish Commonwealth was located at the crossroads of the ideological confrontations of that era.

From the conflicts between Marxism and analytical philosophy, materialism and spiritualism, imported ideology and national tradition, from the struggle between Soviet and American cultural influences, from the melding of Swedish and Yugoslav concepts of socialism, an authentically new Polish society is slowly and painfully being born.

Taking into account those two fundamental parameters of the developing social situation in Poland, we can say that the new generations of Poles will more and more focus on sociocultural achievements. I fully agree here with Professor Andrzej Sicinski who said recently that: "in the perspective of year 2000 (and maybe much earlier) the development of culture will become the most essential element in the entire development of our country." But this is possible and probable only if, as Siciński also points out, the political competition between capitalist and socialist-Communist systems largely gives way to cultural competition.

Class divisions in Poland will survive, although their relative character will change. The working class is expected to grow more slowly but its dynamics will be strengthened. The future of the peasantry is dependent upon three factors: (1) the mechanization and specialization of agricultural productivity, resulting from various external stimuli including an improvement in educational standards; (2) a continuation of healthy competition between individual farming and state control, and (3) a restoration of the prestige of work in agriculture in the wake of the world-wide criticism of man's relations with nature.

The intelligentsia is expected to continue its growth and to be divided more distinctively into two parts: (1) the various occupational subgroups, including experts, constituting a new middle class similar to that of advanced Western societies; and (2) the creative intelligentsia, which will continue to be both value carriers of national tradition and the defenders of universal ideals. Bureaucratization will remain a great problem, entailing a continuing increase of "office workers" and administrators within the new middle class. Yet, in defining its social role, the Polish intelligentsia will have a distinct advantage over the middle class in the West, at least as long as the humanistic tradition of Polish education survives the onslaught of modernization. 


\section{A. Styputkowski:}

Not long ago the Soviet Union celebrated fifty years of existence. This coincided with the era of détente, with the partial opening of frontiers, and with the emergence of the dissident movement. All of these provided us with closer insight into the phenomenon of the so-called homo-Sovieticus. We have no time, of course, to analyze this phenomenon in detail, but, nevertheless, I would like to give one example to illustrate my point.

You may be familiar with the name Victor Feinburg, one of the leading Soviet dissidents who demonstrated on Red Square in 1968 against the invasion of Czechoslovakia. He was punished for it by being put into a mental prison hospital and tortured there; but he was finally released and now lives in the West. During these tragic experiences he was helped by a brave Soviet doctor by the name of Marina Voikhanskaia who has now become his wife. After reaching Geneva, Dr. Voikhanskaia was asked by the Western journalists whether her colleagues, the Soviet psychiatrists, or the Soviet public at large supported her in her endeavors to help the victims. "Well," her answer was, "well, yes, there are many brave people in the Soviet Union and they were sympathizing with the victims, but I am absolutely sure that the majority of my colleagues were convinced that to demonstrate on Red Square in 1968 was evidence of some form of mental derangement."

In twenty years time, in 1995, Poland will be celebrating its fifty years of Communist rule, and as Professor Leszek Kolakowski pointed out in 1973 in Kultura, there is a real danger in present-day Poland of the Sovietization of Polish life along the same lines. The Poles, of course, distrust the press and the mass media and yet the "double talk" to which they are submitted day in and day out, the "double think" which prevents them from calling a spade a spade, must undoubtedly make some impact upon them. This process of mental erosion is progressing as time goes by.

Yet, there are also strong forces counteracting and even successfully arresting this process. One of them is the church, to which Professor Gella has already referred. Irrespective of the Vatican's Eastern policy and its establishment or nonestablishment of diplomatic relations with People's Poland, the struggle for the nation's soul will continue in the next twenty-five years. I think the church has a good chance to resist and, indeed, to win in the end. The outcome will depend to a large extent on the intellectual, civic, and even political abilities of the future Polish clergy.

The other very important element is the family. It is a truism, of course, to say that throughout Poland's history the family has always been the basic cell preserving the traditional national values of liberty, freedom, patriotism, and so forth. This was true during the era of partitions and it is true also today. How highly valued the family is in Polish life, and especially among 
the youth, was recently demonstrated by the results of an opinion poll conducted by the Warsaw Polityka. The results showed that the value which youths between 16 and 19 , representing various social strata and various parts of the country, said they cherish most is family attachment and that the most important aspect of human life is happiness in the family.

There are many other aspects of this opinion poll which are relevant to our discussion, but one thing that ought to be emphasized is that the clichés describing the young Polish generation, and especially the teenagers, as being materialistic and opportunistic are absolutely untrue. I think we are witnessing a kind of ideological revival, a new wave of the traditional Polish romanticism, if you like. Indeed, there may also be a danger in this process. Among the values which were traditionally passed from father to son in Poland was that of patriotic outbursts - the military uprisings. We are now nearing the point at which the fathers of the Polish families will be those who have never taken part in military struggles-but this does not necessarily exclude the possibility that the same tradition will continue.

Still another element of continuity is the traditional peasant culturewill it break or will it continue as it has until now? Professor Fallenbuchl has explained the processes which are now in progress in the countryside. All I could add to this is to quote one Polish commentator, Mr. Aleksander Małachowski, who recently drew our attention to the fact that the transformation of the Polish peasant community would have an important overall effect on the psychological transformation of the nation from the post-szlachta mentality to a post-peasant outlook. With the steady migration from land to town, will the conservative resilience of the Polish peasants continue or will it cease?

Finally, one should mention the traditional links between Poland and the West. In contrast to the Soviet Union, Poland's geographical proximity to and spiritual affinity with Western Europe will continue to play a significant role. The Poles, one should add, generally do have a fairly accurate picture of developments in the West. I think, however, that the traditional idolizing of the West in Poland will cease, or perhaps it has even already ceased because of the crisis of confidence in Western institutions. It will depend primarily on developments in Western societies whether the traditional attraction of the West survives in Polish society.

\section{Chairman:}

We have heard comments from all five panelists, and I should like to point out two issues which are especially ripe for the first round of our discussion.

I was much impressed by the four alternative models of Poland's future which Professor Brzeziński presented to us. As you recall, these were: 
(1) independence à la 1918-1939; (2) evolution in the direction of democracy and closer links with Western Europe; (3) maintenance of status quo, in other words a continuation of dependence on the USSR as today; and finally, (4) absorption of Poland into the Soviet Union. It is rather significant, I think, that at least three panelists were optimistic about the chances for the realization of the second alternative.

However, there was also considerable pessimism in what Zbigniew Fallenbuchl had to say about future economic trends. The conclusion that I draw from his remarks is that sheer economic necessity will push the Communist leadership into more centralized economic planning, and, thus, away from democratic reforms. Some pessimistic overtones also were apparent in what Zbigniew Brzeziński said about the possibility of emergence of a militaryideological regime in the Soviet Union which would harden the division of the world into two blocs and thus limit Poland's chances of gradually expanding its relations with the West. Perhaps we should elaborate a bit on that. Professor Brzeziński, would you like to add something to your earlier comments?

\section{Z. Brzeziński:}

All I can do really is to dwell on what I said earlier. I fully agree with what Professor Kołakowski has said about the erosion of Communist ideology in both the Soviet Union and Poland in the sense that it is no longer a creative, vital force which commands the intellectual as well as the personal commitment of individuals. It is still, however, an institutional force that is deeply embedded in the existing bureaucracies and, therefore, its function is different. Instead of a revolutionary relationship to reality, it has now acquired a conservative relationship to reality. Earlier, the ideology was to try to change the world or society; today, it serves to preserve the power of those who hold power. Because it is conservative it has to be imbued with something more emoticnal than just vested interest. That vacuum in the Soviet Union, in my judgment, is being filled increasingly by traditional nationalism-particularly Great Russian nationalism, which is now much more imbued with great-power aspirations. The carrier of that nationalism in the Soviet Union is the military. We thus witness in the USSR a very interesting new development: the militarization of the social ethos. In the Soviet Union, that is going to have very conservative implications. I do not want to comment at this stage about changes in Poland, but perhaps Professor Kołakowski would do that.

\section{Kolakoweski:}

I would say that while the trend toward the ruling ideology is becoming 
increasingly nationalistic and is, indeed, noticeable in the Soviet Union, it is extremely unlikely that something like a military takeover could occur in the USSR-at least without undermining the whole existing system of power. The Soviet Union throughout its entire history has never been ruled either by the military or by the police. True, during the Stalinist period it was ruled only in name by the party, while Stalin ruled the party itself with the help of the police. Yet, and this is an important distinction, he ruled as a party leader and not as a police chief, because only the party is supposed to articulate the interests and the aspirations of the society as a whole and no other organization within the Soviet society can make such claims.

It is unlikely, then, that the country could be ruled overtly under Russian nationalistic slogans without jeopardizing the whole system of power and releasing all the most dangerous, nationalistic, anti-Russian forces. It is for those reasons that such a scenario seems to me unlikely. It is, of course, possible, as Professor Brzeziński has pointed out, that the nationalist tendency will be increasingly articulated openly without the Marxist phraseologywhich in any case becomes more and more grotesque when confronted with reality-and this may lead to a very serious crisis in the country.

Also, I think it is likely that as a result of the increasingly nationalistic trends in Russia, Polish ideological life also will focus more and not less on nationalistic alternatives and nationalistic patterns. I am not saying that I am happy about this, but I think it is very likely. And this may happen in spite of the processes at work in Poland, as in all the rapidly industrializing societies, in which industrialization is normally associated with certain decline in religiosity. This process is going on in Poland-in fact it has been going on during the entire postwar period-but at the same time there is a reverse trend in the attraction to religion and the Catholic tradition among the intellectuals and among the young people, which is something that nobody really expected. If, as is likely, this trend continues, it means that the Catholic culture in Poland is now in a phase of development and expansion.

Catholicism at present, in my opinion, is much better than it used to be before the war; it is more flexible and open, and intellectually at a higher plane. It is likely, of course, that with the decreasing role of the peasantry in Poland the old models of Christianity and of Christian life, which were patterned mostly on the rural communities, will decline. This does not mean, however, that religiosity or Christianity as such will necessarily decline. Rather the opposite may be expected. But I. would be reluctant to make any prophecies about the ultimate outcome of all these trends.

\section{Z. Fallenbuchl:}

This is not really my field, but I cannot resist the temptation to offer 
some observations. I believe that ideology is at present being replaced by the interest of the state, as defined by the bureaucrats. Poland today is a typical bureaucratic country, and whatever bureaucracy is doing is explained as being in the interest of the state! Almost everything is explained by reference to the state's rights-the state must have the right to do this and that. . . This, in effect, has become a substitute for ideology. The cohesive power among the bureaucracy nowadays can be described by a good Polish word: sitwa. You support someone else because you want his support and he supports you because he needs your support, and somehow the bureaucracy manages to keep going.

\section{A. Gella:}

I would like to make several comments in response to Mr. Stypułkowski, first of all regarding the danger of the emergence of homo-Sovieticus in Poland. I am not particularly concerned about that because especially since 1956, we have seen the development of more and more infrastructures in Poland: that is, informal groups in which people are able to speak their minds quite openly and without any "double thinking" whatsoever. That is one of the ways through which this danger is deliberately averted.

As to the problem also raised by Mr. Stypułkowski of the peasant culture becoming dominant in Poland, it seems to me that, on the contrary, the peasants who are moving upward through the educational system are being assimilated within the traditional national Polish culture. Of course, this national culture is threatened by modernization in the general sense of the term, but this is a different subject. Generally speaking, it has proven impossible in Poland to produce a peasant intelligentsia, despite the huge number of peasants who in the postwar years became the so-called working intelligentsia.

One last point. I think it is important to remember something which foreigners often tend to ignore, and that is that in Poland there is traditional distinction between nationalism and patriotism: nationalism has always been a political ideology, while patriotism is simply the love of one's country. 